ISSN 2079-9292

www.mdpi.com/journal/electronics

Review

\title{
Organic Thin-Film Transistor (OTFT)-Based Sensors
}

\author{
Daniel Elkington *, Nathan Cooling, Warwick Belcher, Paul C. Dastoor and Xiaojing Zhou \\ Centre for Organic Electronics, Physics, The University of Newcastle, Callaghan, NSW 2308, Australia; \\ E-Mails: nathan.cooling@newcastle.edu.au (N.C.); warwick.belcher@ newcastle.edu.au (W.B.); \\ paul.dastoor@newcastle.edu.au (P.C.D.); xiaojing.zhou@ newcastle.edu.au (X.Z.)
}

* Author to whom correspondence should be addressed; E-Mail: daniel.elkington@ newcastle.edu.au; Tel.: +61-2-4921-6732; Fax: +61-2-4921-6907.

Received: 23 January 2014; in revised form: 25 March 2014 / Accepted: 27 March 2014 /

Published: 8 April 2014

\begin{abstract}
Organic thin film transistors have been a popular research topic in recent decades and have found applications from flexible displays to disposable sensors. In this review, we present an overview of some notable articles reporting sensing applications for organic transistors with a focus on the most recent publications. In particular, we concentrate on three main types of organic transistor-based sensors: biosensors, pressure sensors and "e-nose"/vapour sensors.
\end{abstract}

Keywords: OTFT; sensor; review

\section{Introduction}

Organic thin-film transistors (OTFTs) have been the subject of much attention in the scientific research community in recent decades [1,2]. Due to their potential to be low-cost and their ease of fabrication, OTFTs seem ideal for use in sensing applications in which there may be a desire for cheap, single-use or disposable devices that can deliver accurate results. For example, an array of sensing devices can be printed in one device to realize a true "lab-on-chip" proposition for determining the concentration of certain target analytes in a sample. In addition, organic materials are more likely to be compatible with highly selective biological recognition elements, such as enzymes, which can form the basis for effective sensors. 
There have already been many review articles in recent years summarizing research into sensing devices that integrate OTFTs into their architecture. This review intends to focus on articles that have reported OTFT-based sensors falling into one of three categories-biosensors, pressure sensors and those detecting vapour-phase analytes for "electronic nose" applications - for the authors feel these three types of sensor are the least explored by other reviews in this highly dynamic field. Some historically significant papers in the chosen areas will be introduced in each section initially, before the focus is turned to papers contributing to the respective fields more recently. This scope was determined both by the interests of the authors and also the desire to avoid repetition through the review of some types of OTFT-based sensors, such as those detecting $\mathrm{pH}$, humidity or certain ionic species, which have been given the most attention in some recent review articles on organic transistor-based sensors as a whole $[3,4]$. One exception to this scope is biosensors based on proton-liberating enzymatic reactions, which can also be regarded as pH sensors [5], that are included here as enzyme-based biosensors.

\section{Organic Thin Film Transistors}

OTFTs are three-terminal electrical devices that, much like conventional transistors, allow for the control of the electrical current flowing between two electrodes (source and drain) through the modulation of voltage (or current) at a third electrode (the gate). The term OTFT can be generically used to refer to most types of organic transistor; however (depending on the mechanism used to achieve the current modulation), organic transistors are typically categorized into one of several categories. These categories include (but are not limited to):

- Organic field effect-transistors (OFETs): OFETs operate in a similar way to conventional MOSFET (metal-oxide-semiconductor field effect transistor) or TFT (thin-film transistor) devices in which an electric field is established across a dielectric layer separating the gate electrode from the semiconductor layer (Figure 1a). This electric field can manipulate the size and shape of a region of high conductivity in, and hence, modulate the current flowing through, the semiconductor material, creating a relationship between gate voltage $\left(\mathrm{V}_{\mathrm{G}}\right)$ and drain current $\left(\mathrm{I}_{\mathrm{D}}\right)$.

- Organic electrochemical transistors (OECTs): OECTs operate by inducing a reduction or oxidation reaction, which influences $\mathrm{I}_{\mathrm{D}}$, due to a voltage at the gate electrode. Often, these devices can resemble conventional three-terminal electrochemical cells in which the source, drain and gate electrodes play the roles of the working, counter and reference electrodes. Other types of OECTs more closely resemble a standard OFET in which some electrochemical reaction is taking place at an interface of the semiconductor to facilitate current modulation. Many of the other categories of devices listed below could be thought of as sub-categories of OECTs.

- Electrolyte-gated organic field effect transistors (EGOFETs): EGOFETs employ an electrolyte layer (in either a solid or liquid form) to separate the gate electrode from the semiconductor layer (Figure 1b). This electrolyte layer allows for ionic movement within it, and this leads to the build-up of charge at its interfaces and subsequent electrochemical reactions. One advantage of EGOFETs is their low operating voltage; however, they can suffer from poor switching speeds, due to their reliance on electrochemical activity [6]. EGOFETs featuring ion-selective membranes, which could improve their ability to be applied in sensing applications, have also been successfully demonstrated recently [7]. 
- Ion-sensitive OFETs (ISOFETs): an analogue to the ion-sensitive FET (ISFET) family of silicon-based devices, ISOFETs are similar to EGOFETs in that they have an electrolyte layer adjacent to the gate electrode (Figure 1c). However, unlike EGOFETs, ISOFETs also have a dielectric layer, which isolates the electrolyte from the semiconductor [8].

- Hygroscopic-insulator field effect transistors (HIFETs): HIFETs could be considered a sub-category of both OECTs and EGOFETs. Initially proposed by the group of Österbacka et al. [9], HIFETs rely on the hygroscopic nature of their dielectric layer to create a moist environment for the free movement of ions within it. These ions then can interact with the semiconductor at the dielectric/semiconductor interface electrochemically and/or electrostatically to modulate current through the semiconductor (i.e., $\mathrm{I}_{\mathrm{D}}$ ) by varying $\mathrm{V}_{\mathrm{G}}$.

- Carbon nanotube FETs (CNTFET or NTFETs): these devices use one or many carbon nanotubes as the material (semiconductor) connecting the source and drain electrodes (Figure 1d). CNTFETs are seen as promising devices for use in all types of electronics, due to the excellent electronic properties of carbon nanotubes (CNTs) [10]. In terms of biosensors, encapsulation by CNTs has been shown as an effective way to immobilise bio-recognition elements [11].

- Organic charge-modulated FETs (OCMFETs): OCMFETs are a relatively new category of organic transistor, which have been proposed by the group of Bonfiglio et al. specifically for the purpose of sensing, and are somewhat similar in structure to ISOFETs [12,13]. However, OCMFETs have two gate electrodes: one, a "reference gate", which is held at a fixed electrical potential (biasing the device), as well as a "floating gate", which is coupled to the other gate electrode and to the rest of the device through a common dielectric layer (Figure 1e). The floating gate is electrically connected to the "sensing area" upon which charge is accumulated, depending on the quantity of analyte present. Two of the main claimed advantages of OCMFETs is that they can be miniaturised relative to similar devices implementing a reference electrode and also that the semiconductor is not directly exposed to analyte solution.

Figure 1. Simplified diagrams of various types of organic thin-film transistor (OTFT): (a) organic field effect-transistor (OFET) (bottom-gate, top-contact version shown); (b) electrolyte-gated organic field effect transistor (EGOFET); (c) ion-sensitive OFET (ISOFET); (d) carbon nanotube FET (CNTFET); and (e) organic charge-modulated FET (OCMFET).
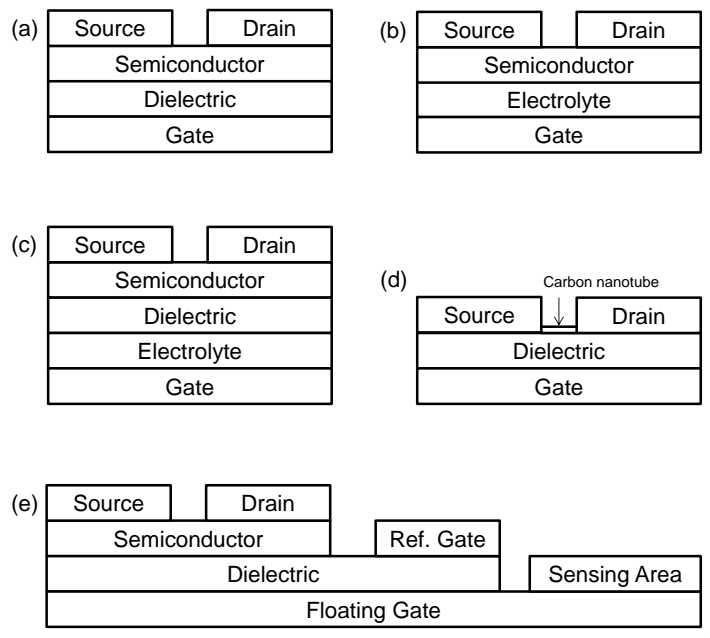
OTFTs are well-suited for use in biosensing applications, due to the biocompatibility of the materials used with biological recognition elements, such as enzymes [14]. Traditional electronic materials, such as silicon and metals, require high processing temperatures and are non-porous and, as such, are not well suited for incorporating enzymes, which denature at high temperatures and require direct contact with their target analyte molecules. In addition, the low-cost fabrication possibilities of organic electronic materials increase their practicality in throw-away applications in which sensors may be desired to be used. Furthermore, the drawbacks of organic semiconductors, such as their relatively low charge carrier mobility, which prevents them from competing with their conventional counterparts (such as silicon) in applications requiring high switching speeds, for example, are less crucial to many sensing applications, in which taking tens or even hundreds of seconds to generate a detection result is quite acceptable. In addition, organic semiconductors, such as poly(3-hexylthiophene) (P3HT), can be readily modified through the deposition of a thin interfacial layer in order to immobilize biological recognition elements for use in OTFT-based sensors [15].

\section{Biosensors}

Detecting and measuring the concentration of certain biological moieties is critical to many medical and other scientific applications. For example, some of the analytes targeted by sensors discussed below in this review are markers that show the presence or onset of disease or other health problems. However, before examining the existing research in the area of organic transistor-based biosensors, it is worth defining what constitutes a biosensor, since various definitions of a biosensor have been proposed within the existing body of literature. For the purposes of this review, as in the previous review by Kergoat et al. [6], we will use the IUPAC's "Gold book" definition, which considers any device that "uses specific biochemical reactions mediated by isolated enzymes, immunosystems, tissues, organelles or whole cells to detect chemical compounds usually by electrical, thermal or optical signals" to be a biosensor [16], and this review will focus on those devices with an electrical output integrated with one of the many varieties of OTFT.

Biosensors have enjoyed steady development since the earliest papers on the subject were published (such as the 1962 report by Clark and Lyons [17]). There have been some excellent review articles summarizing publications on biosensors employing organic electronics in recent years $[3,4,6]$. However, in this highly dynamic area, improvements to the selectivity and resolution of sensors, as well as the introduction of new materials are often being reported, as research groups gradually develop devices with a view toward commercial use in the not-too-distant future.

This review will summarize the field with a focus on recent advances, and the publications discussed will be organized into three sections. The first section focusses on those sensors detecting glucose enzymatically using glucose oxidase (GOx), since this system has had much attention in the development of new methods and platforms for biosensing. The next section is dedicated to sensors based on enzymes other than glucose oxidase, since the number of publications using non-GOx enzymes has increased recently. Thirdly, sensors that detect biological analytes by non-enzymatic mechanisms will be discussed in the third section. Any types of sensors involving inorganic semiconductor layers in their transistor will not be covered in this review. 


\subsection{Enzymatic Glucose Sensing}

The detection of glucose using GOx has long been used as a model detection system [18] and has been included in biosensor studies going back to the 1960s [17]. This extensive use can be attributed to three reasons. Firstly, the reaction with glucose, which is catalysed by glucose oxidase, has been very clearly defined and well understood for many years, making it ideal for use in situations with other unknown factors, such as newly-developed sensing platforms. Indeed, the high stability and specificity of GOx has led to it being referred to as "the ideal enzyme" [19]. Secondly, $\mathrm{H}_{2} \mathrm{O}_{2}$, a by-product of the glucose-GOx reaction, can electrochemically react with (oxidize) conjugated polymers, causing a change in conductivity [20], as well as an electrochemical break down when exposed to an electrical potential into by-products, including charge carriers, making for two potential sources of generating an electrical signal (see Equations (1) and (2)). Thirdly, and crucially, the sensing of glucose has many extremely useful medical applications; in particular, for the monitoring of blood-glucose levels in sufferers of diabetes.

$$
\begin{aligned}
& \text { Glucose } \underset{\text { GOX }}{\longrightarrow} \text { Gluconic acid }+\mathrm{H}_{2} \mathrm{O}_{2} \\
& \mathrm{H}_{2} \mathrm{O}_{2} \underset{0.7 \mathrm{Vvs} \mathrm{SCE}}{\longrightarrow} \mathrm{O}_{2}+2 \mathrm{H}^{+}+2 e^{-}
\end{aligned}
$$

As early as the 1980s, there have been reports of enzymatic glucose detection using GOx along with organic electronic materials, such as polypyrrole (PPy). Typically, the method reported involved using conventional electrochemical techniques, such as cyclic voltammetry [21,22]. In more recent years, there has been increased attention on developing a more fully integrated sensor using GOx as the detection mechanism and OTFTs to provide the electrical signal to be measured.

In 2004, Zhu et al. demonstrated an OECT-based sensor in which PEDOT:PSS was the semiconducting layer of the transistors, and a "well" (constructed from polydimethylsiloxane (PDMS)) was formed above the channel of the devices to hold both the analyte solution and a platinum gate electrode, which was suspended in the analyte solution [23]. In 2007, this work was expanded upon when various concentrations of glucose solutions were mixed with GOx and added to the well of the transistors, after which the change in resistance of the PEDOT:PSS layer was measured [20]. The results indicated that the proposed device structure was more effective than a plain "chemiresistor" (i.e., the same device with no gate electrode), since the sensitivity of the device was greatly improved with a voltage applied to the gate (Figure 2), and sensitivity in the micromolar range was achieved. In a subsequent paper using devices of a similar structure, the "offset voltage" (the difference between the applied $V_{G}$ and the effective $V_{G}$ "seen" by the device) was found to depend on glucose concentration and was used as the dependent variable in calibration curves [24]. 
Figure 2. Normalized resistance between the source and drain for Organic electrochemical transistors (OECTs) exposed to different concentrations of glucose solution, at $\mathrm{V}_{\mathrm{G}}$ values of $0.1 \mathrm{~V}$ and $0.6 \mathrm{~V}$ and with no gate connection.

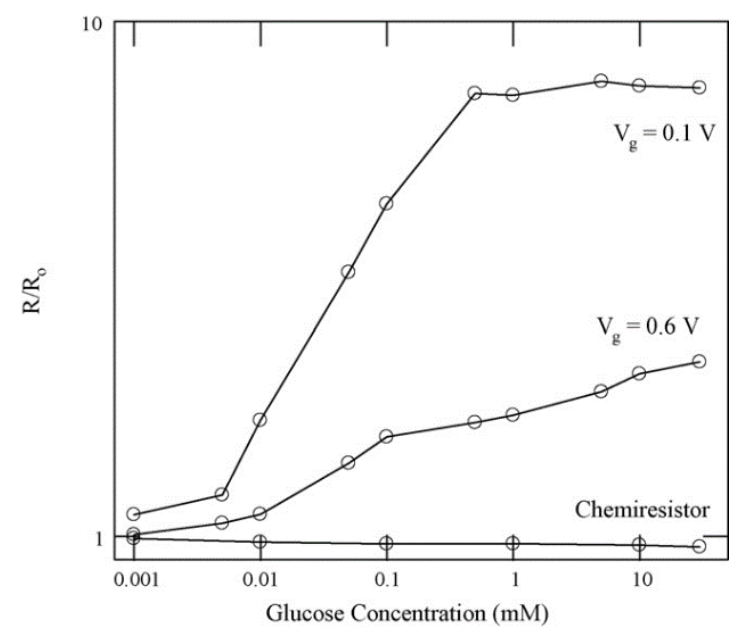

Reprinted from Sensors and Actuators B: Chemical, 123(1), Macaya et al., Simple glucose sensors with micromolar sensitivity based on organic electrochemical transistors, 374-378, Copyright (2007), with permission from Elsevier [20].

Another approach used a different design of integrated sensor in which the enzyme was mixed into a phosphate buffer solution and spin-coated to form a film on top of the PEDOT:PSS semiconductor layer joining the source and drain [25]. When $\mathrm{V}_{\mathrm{G}}$ and the drain voltage $\left(\mathrm{V}_{\mathrm{D}}\right)$ were fixed at a given value, it was found that $I_{D}$ increased as a function of the glucose concentration of a solution that was dropped on top of the device. The devices showed a linear relationship between the change in their $I_{D}$ after analyte addition and glucose concentration in the one to $20 \mathrm{mM}$ range (sensitivity $=1.65 \mu \mathrm{A} \cdot \mathrm{mM}^{-1}$ ), with a response time in the order of $20 \mathrm{~s}$.

More recently, Liao et al. have used GOx embedded into graphene or reduced graphene oxide (rGO)-modified gate electrodes with which linear glucose sensing in the range of $10 \mathrm{nM}$ to $1 \mu \mathrm{M}$ is achieved [26]. The high surface area of the graphene/rGO allowed for a two orders of magnitude increase in the detection limit. The selectivity of the sensors due to the presence of glucose oxidase was demonstrated by presenting analyte solutions of both uric acid and L-ascorbic acid, as well as glucose to devices with and without the enzyme present. The enzyme-containing devices showed a much higher response to glucose, whilst the level of response to the analytes in the enzyme-free devices was comparable. The same group has also gone on to produce dopamine sensors of a similar structure with graphene/rGO, again improving device sensitivity [27]. Furthermore, in 2011, Tang et al. showed that the sensitivity of glucose detectors can be improved when GOx is used in conjunction with nanoparticles to improve the effectiveness of how the enzyme is immobilized on the devices [28].

One of the disadvantages of most of the OTFT-based enzymatic glucose sensors reported so far in the body of literature is their relatively slow response speed, often in the tens or hundreds of seconds, and improving this parameter may be a goal of future research in the area. However, for many sensing applications, this may not be an issue, since for applications, such as determining the concentration of glucose in the blood of a diabetes sufferer, these slow response speeds are not important. In addition, 
response speeds of these prototype devices are likely to improve as the most promising types of sensors undergo further refinements.

\subsection{Other Enzymatic Sensors}

Although the reaction between glucose and GOx has arguably attracted the majority of attention historically, when it comes to OTFT-based enzymatic biosensors, the majority of recent reports focus on other enzymes, which can be integrated into organic transistors to generate an electrical signal related to the concentration of their target analyte. In this section, some interesting articles from recent years reporting enzymatic sensors with non-GOx recognition elements are introduced. Also included is a short discussion of some publications reporting enzymatic sensors, which, although not incorporating organic transistors into their design, use processing steps or fabrication methods compatible with OTFT-based designs and may be of interest to researchers considering the development of new types of OTFT-based sensors.

Wang and Gao reported in 2010 a method of encapsulating urease into a single-layer PPy membrane for the sensing of urea, a substance present in blood that can be a biomarker for some serious illnesses in humans and other animals, depending on its concentration [29]. The PPy film was electro-polymerized in the presence of the enzyme creating a thin film, which was subsequently used as the recognition element in a "BioFET", which achieved the linear detection of the analyte from $0.1 \mu \mathrm{M}$ through to $1 \mathrm{mM}$ in a phosphate buffer solution.

In 2012, Buth et al. reported the detection of penicillin using solution-gated organic field effect transistors (dubbed "SGFETs") with a penicillinase-functionalized $\alpha$-sexithiophene semiconductor, which rely on the $\mathrm{pH}$-sensitive nature of the $\alpha$-sexithiophene combined with the proton-liberating enzymatic reaction for their operation [30]. The sensitivity is claimed to be at least as good as similar inorganic sensors (as high as $80 \mu \mathrm{V} \cdot \mu \mathrm{M}^{-1}$ ). In 2013, Khodagholy et al. demonstrated OECTs with lactose oxidase incorporated into an "ionogel" on top of the devices [31]. The sensors can detect lactate down approximately to $10 \mathrm{mM}$.

Some other recent publications report enzymatic sensors, which although not employing transistors in their architecture, involve fabrication techniques that could be applicable for use in sensors that do incorporate OTFTs. For example, Phongphut et al. reported the sensing of triglyceride, a biomarker for some serious diseases, by immobilizing three different enzymes (lipase, glycerol kinase and glycerol-3-phosphate oxidase) onto a working electrode fabricated using a PEDOT:PSS/gold nanocomposite material [32]. The three enzymes act on triglycerides in subsequent steps to liberate $\mathrm{H}_{2} \mathrm{O}_{2}$, which can be detected electrochemically, and a low detection limit of $7.88 \mathrm{mg} \cdot \mathrm{dL}^{-1}$ was achieved. Another example was reported in a 2013 publication from Jia et al. in which a novel electrochemical sensor was fabricated in the form of a "temporary-transfer tattoo" capable of continuous sensing lactose levels in human sweat (Figure 3) [33]. Lactate is a biomarker for tissue oxygenation, critical in assessing physical performance in sports and other healthcare areas. High selectivity was displayed, with little or no response to uric acid, glucose, creatinine or ascorbic acid. Although the sensor does not incorporate an OTFT and required a connection to an external potentiostat in the same way as a conventional electrochemical cell, it was fabricated largely from printing techniques and solution-based materials, making it compatible with and perhaps able to be 
improved by organic transistors. Finally, sub-millimolar sensing of urea (which when found in the body in excessive quantities is a sign of kidney malfunction) using urease-functionalized polyaniline and poly(vinylsulfonic acid) $\mathrm{pH}$-sensitive membranes incorporated onto working electrodes in an electrochemical cell was recently reported by Vieira and co-workers [34]. This type of device is also known as a separative extended gate field-effect transistor (SEGFET), since the gate is separated from the rest of the device by the solution in the cell.

Figure 3. (a) The intensity profile of an exercise routine; (b) a photograph of the lactose-sensing transfer tattoo; and (c,d) current versus time for the devices with (red) and without (blue) the enzyme present whilst the athlete is performing the exercise routine with the intensity profile shown in (a).
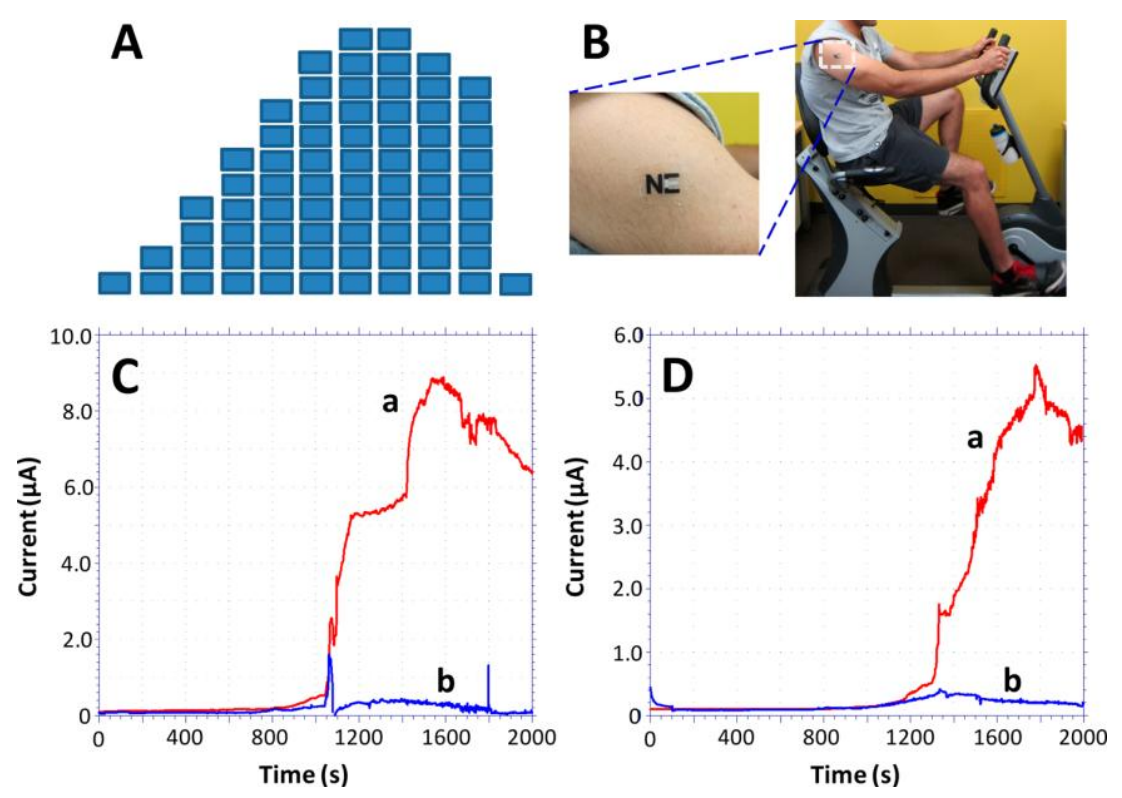

Reprinted with permission from Analytical Chemistry, 85, Jia et al., Electrochemical tattoo biosensors for real-time non-invasive lactate monitoring in human perspiration, Copyright (2013) American Chemical Society [33].

\subsection{Non-Enzymatic Biosensors}

Enzymes which catalyse charge carrier-liberating reactions are arguably the most well-suited recognition elements for OTFT-based biosensors, due to their inherent selectivity; however, there have also been many non-enzymatic sensors reported recently, which are being shown to be highly effective. Some of the most common recognition elements used in this category of sensors include other (non-enzyme) proteins and antibodies. There are also sensors in this category that do not employ highly specific recognition elements and, instead, rely on electrochemical reduction and/or oxidation reactions induced by an electrical potential. Although such devices by their nature may suffer from poor selectivity, they can have very high sensitivity and may still function as useful sensors if the sensitivity to the target analyte is relatively high compared with other moieties found in typical samples related to the application.

In a report from 2002, Someya et al. presented an early example of an organic transistor-based biosensor based on electrochemical detection (i.e., no specific receptor/recognition element was used). 
Lactic acid was detected at concentrations down to $10 \mu \mathrm{M}$ using organic transistors with $\alpha$-sexithiophene $(\alpha 6 \mathrm{~T})$ and copper phthalocyanine $(\mathrm{CuPc})$ [35]. Since then, many other types of non-enzymatic biosensor have been reported in the literature.

Biotin detection at concentrations as low as $15 \mathrm{pM}$ has been reported recently by Magliulo et al. using OFET-based biosensors employing a "functional bio-interlayer" (FBI) as the material connecting the source and drain (see Figure 4) [36]. The FBI consists of two materials: streptavidin (SA), a protein that has an extremely high affinity to biotin, and the organic semiconductor, P3HT. The protein layer was deposited both by spin-coating and by a self-assembly process, with these two deposition techniques for SA showing comparable performance. When the transfer characteristics of the devices were measured with aqueous solutions of biotin of various concentrations dropped on top of the device, $\mathrm{I}_{\mathrm{D}}$ was found to decrease with increasing biotin concentration, due to a change in the P3HT layer's electronic properties upon binding of biotin by the SA. Successful sensing trials were also conducted in which the SA layer was replaced firstly with a biotin antibody and secondly with the enzyme, horseradish peroxidase, showing that the "FBI-OFET" may be a promising platform for a variety of biological recognition elements. In a previous paper from the same group, biotin was also successfully immobilized on an organic semiconductor layer in an EGOFET, and SA was used as the target analyte [37].

Figure 4. (a) Cross-sectional diagram of functional bio-interlayer (FBI)-OFET with a streptavidin layer for the detection of biotin; (b) the output characteristic of the biotin-sensing FBI-OFET. Reproduced from [36].

(a)

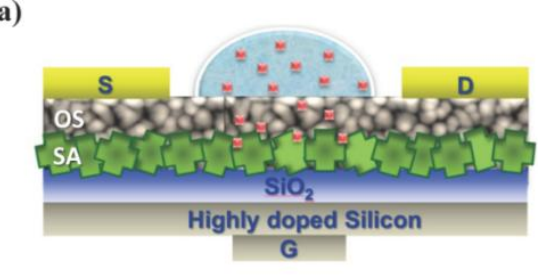

(b)

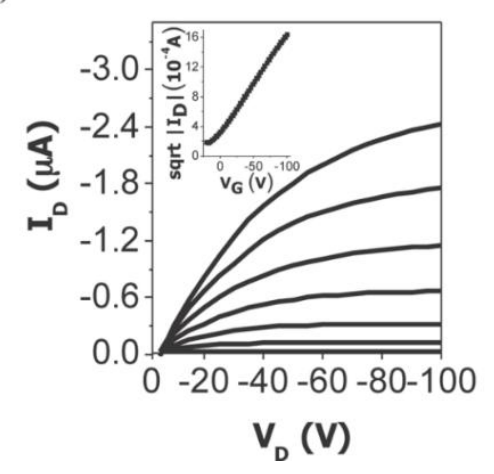

Justino et al. have recently reported a C-reactive protein (CRP) detecting NTFET, capable of sensing analyte concentrations of $10^{-4}$ to $10^{2} \mu \mathrm{g} \cdot \mathrm{mL}^{-1}$ [11]. This range of concentrations covers the critical range of around one to $10 \mu \mathrm{g} \cdot \mathrm{mL}^{-1}$, in which CRP is an important biomarker for conditions, such as cardiovascular disease. The use of a simple OTFT-based sensor is appealing, as many conventional detection methods (immunoassays) for CRP are expensive. This NTFET-based device utilizes CRP antibodies by immobilizing them on the surface of the CNT joining the source and drain 
electrodes, and the change in current between the source and drain when different concentrations of CRP were deposited on top of the device was used as the calibration parameter (Figure 5).

Another recent report on an organic biosensor using antibodies as the recognition element published by Chartuprayoon et al. employed very thin strips (so-called "nanoribbons") of PPy as a semiconductor layer [38]. Here, the cucumber mosaic virus (CMV) was detected with CMV antibodies. Although the device used in this study could perhaps be most correctly classified as a chemiresistor (rather than an organic transistor), its structure is such that it could easily be adapted to include a gate electrode. This change in architecture could potentially increase performance, as seen with some other sensing systems, which showed an enhanced response when a potential was added at a third electrode in comparison with the chemiresistor case [20].

Figure 5. Calibration curve for the OTFT sensor-based detection of C-reactive protein (CRP).

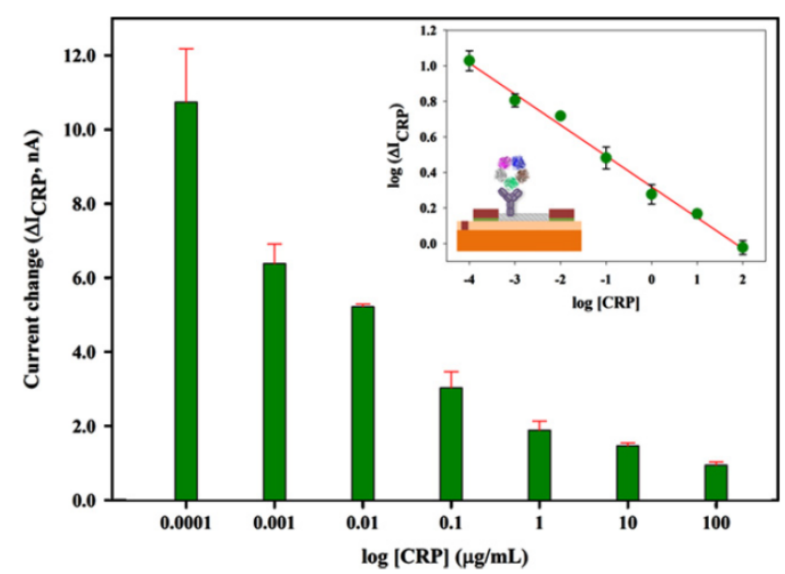

Reprinted from Talanta, 108, Justino et al., Disposable immunosensors for c-reactive protein based on carbon nanotubes field effect transistors, 165-170, Copyright (2013), with permission from Elsevier [11].

The detection of DNA, which is important in many medical applications, is also a popular area of research for organic transistor-based biosensors. In 2010, Lin et al. showed the detection of DNA using organic field effect devices incorporating single-stranded DNA as the recognition element (ssDNA) [39]. DNA was successfully detected down to concentrations of $1 \mu \mathrm{M}$. Furthermore, in 2010, Kahn et al. exhibited DNA detection as low as $1 \mathrm{nM}$ using peptide nucleic acid (PNA) as a recognition element [40]. Since then, several other publications have exhibited DNA sensing using a similar detection mechanism incorporated onto different types of transistors [41-43].

Hammock et al. have recently reported on a thrombin sensor based on an OFET, capable of detection down to approximately $100 \mathrm{pM}$ [44]. The sensor is comprised of a standard bottom-gate, top-contact OFET, with the sensing layer located adjacent to a polymeric semiconductor layer on top of the devices. The recognition elements in these sensors are gold nanoparticles, which have been functionalized by thrombin-specific DNA aptamers after being deposited on the semiconductor.

In another recent study, Tarabella et al. demonstrated that OECTs can be very efficient and reliable sensing devices for detecting liposome-based nanoparticles on a wide dynamic range down to $10^{-5} \mathrm{mg} \cdot \mathrm{mL}^{-1}$ (with a lowest detection limit, assessed in real-time monitoring, of $10^{-7} \mathrm{mg} \cdot \mathrm{mL}^{-1}$ [45]. Even more recently, Huang et al. have shown that glial fibrillary acidic protein (GFAP), a biomarker associated with brain injury, can be detected with an OTFT-based biosensor in which its antibodies were 
immobilized on a polymer film on top of the device [46]. Analyte solution is dropped on top of this layer, and changes in $\mathrm{I}_{\mathrm{D}}$ were found to be related to the concentration of GFAP. In 2011, Tang et al. presented the detection of dopamine down to $5 \mathrm{nM}$ concentrations. The detection mechanism was standard electrochemistry using a platinum gate electrode suspended in the analyte solution [47].

The sensing of bovine serum albumin (BSA) and BSA antibodies (antiBSA) has been exhibited by Kahn et al. in a duo of papers released in $2011[48,49]$. For the sensing of BSA, antiBSA was used at the detection element and vice versa. Pentacene was used as the semiconductor in these devices, which after passivation with perfluoropolymer, were found to be air and water stable, broadening their potential applications.

\subsection{Biosensor Summary}

As was seen in this section, organic transistor-based biosensors come in many different architectures and use different mechanisms to liberate electrical signals in response to the concentration of an analyte. The selectivity of devices that use enzymes, antibodies or other highly selective recognition elements in particular show great promise for high-performance, low-cost sensors. Non-specific electrochemical sensing techniques can also be effective, but suffer from a lack of selectivity. The stability of the materials used in biosensors has received a relatively low amount of attention in the literature to this point, although some papers have discussed this critical issue, and Kahn et al.'s study on the stability of passivized devices shows encouraging results [48].

Table 1 shows a summary of the literature discussed in this section. Included in the table is the target analyte, the material used to detect the analyte, the type of transistor (or otherwise) used in the sensor and the upper and lower concentration limits of analyte detection. The range of concentrations that a sensor can detect is not the parameter by which such devices should be measured. Other critical factors that should be considered in order to determine the practicality of sensors include the selectivity of the devices, their sensitivity and their ease of fabrication, amongst others.

Table 1. A summary of the biosensor devices discussed in this review. The bounds on detectable analyte concentrations are given in molar ratios where possible. * Denotes the use of a non-specific electrochemical mechanism. CuPc, copper phthalocyanine; SEGFET, separative extended gate field-effect transistor; SGFET, solution-gated organic field effect; NTFET, carbon nanotube FET; BSA, bovine serum albumin.

\begin{tabular}{|c|c|c|c|c|c|c|}
\hline \multirow[t]{2}{*}{ Analyte(s) } & \multirow[t]{2}{*}{ Recognition Element } & \multirow{2}{*}{$\begin{array}{c}\text { Device Type } \\
\text { OECT }\end{array}$} & \multicolumn{2}{|c|}{$\begin{array}{c}\text { Claimed Lower and Upper } \\
\text { Detection Limit }\end{array}$} & \multirow{2}{*}{$\begin{array}{l}\text { Year } \\
2004\end{array}$} & \multirow{2}{*}{$\begin{array}{l}\text { Ref. } \\
{[23]}\end{array}$} \\
\hline & & & $0.1 \mathrm{mM}$ & $1 \mathrm{mM}$ & & \\
\hline \multirow{5}{*}{ Glucose } & \multirow{5}{*}{ Glucose oxidase } & OECT & $1 \mu \mathrm{M}$ & $30 \mathrm{mM}$ & 2007 & [20] \\
\hline & & OECT & $1 \mu \mathrm{M}$ & $1 \mathrm{mM}$ & 2007 & [24] \\
\hline & & OTFT & $1.1 \mathrm{mM}$ & $16.5 \mathrm{mM}$ & 2008 & [25] \\
\hline & & $\begin{array}{l}\text { OECT (device and } \\
\text { analyte in solution) }\end{array}$ & $5 \mathrm{nM}$ & $>1 \mathrm{mM}$ & 2011 & [28] \\
\hline & & OECT & $10 \mathrm{nM}$ & $1 \mu \mathrm{M}$ & 2013 & [26] \\
\hline Lactic acid & $\mathrm{CuPc} *$ & OFET & $10 \mathrm{uM}$ & $2 \mathrm{mM}$ & 2002 & [35] \\
\hline
\end{tabular}


Table 1. Cont.

\begin{tabular}{|c|c|c|c|c|c|c|}
\hline Analyte(s) & Recognition Element & Device Type & \multicolumn{2}{|c|}{$\begin{array}{c}\text { Claimed Lower and Upper } \\
\text { Detection Limit }\end{array}$} & \multirow{2}{*}{$\begin{array}{l}\text { Year } \\
2010\end{array}$} & \multirow{2}{*}{$\begin{array}{l}\text { Ref. } \\
{[29]}\end{array}$} \\
\hline & & BioFET & $0.1 \mu \mathrm{M}$ & $1 \mathrm{mM}$ & & \\
\hline Urea & Urease & $\begin{array}{l}\text { SEGFET (device and } \\
\text { analyte in solution) }\end{array}$ & $50 \mu \mathrm{M}$ & $10 \mathrm{mM}$ & 2013 & [34] \\
\hline Penicillin & Penicillinase & SGFET & $\begin{array}{c}10 \mu \mathrm{M} \\
\text { (approx.) }\end{array}$ & $600 \mu \mathrm{M}$ & 2012 & [30] \\
\hline & & OECT & $10 \mathrm{mM}$ & $100 \mathrm{mM}$ & 2013 & [31] \\
\hline Lactate & Lactose Oxidase & $\begin{array}{c}\text { Non-transistor } \\
\text { electrochemical device }\end{array}$ & $1 \mathrm{mM}$ & $30 \mathrm{mM}$ & 2013 & [33] \\
\hline Liposome & PEDOT:PSS * & OECT & $10 \mu \mathrm{g} \cdot \mathrm{mL}^{-1}$ & $0.1 \mathrm{mg} \cdot \mathrm{mL}^{-1}$ & 2013 & [45] \\
\hline Biotin & Streptavidin & FBI-OFET & $15 \mathrm{pM}$ & $500 \mathrm{nM}$ & 2013 & [36] \\
\hline Streptavidin & Biotin & FBI-OFET & $10 \mathrm{nM}$ & $1 \mu \mathrm{M}$ & 2013 & [37] \\
\hline $\begin{array}{l}\text { C-reactive } \\
\text { protein }(\mathrm{CRP})\end{array}$ & CRP antibodies & NTFET & $0.1 \mathrm{ng} \cdot \mathrm{mL}^{-1}$ & $100 \mu \mathrm{g} \cdot \mathrm{mL}^{-1}$ & 2013 & [11] \\
\hline $\begin{array}{c}\text { Cucumber } \\
\text { mosaic virus } \\
(\mathrm{CMV}) \\
\end{array}$ & CMV antibodies & Chemiresistor & $1 \mathrm{ng} \cdot \mathrm{mL}^{-1}$ & $100 \mu \mathrm{g} \cdot \mathrm{mL}^{-1}$ & 2013 & [38] \\
\hline Triglyceride & $\begin{array}{c}\text { Lipase, glycerol } \\
\text { kinase and glycerol-3- } \\
\text { phosphate oxidase }\end{array}$ & $\begin{array}{l}\text { Non-transistor } \\
\text { electrochemistry }\end{array}$ & $7.88 \mathrm{mg} \cdot \mathrm{dL}^{-1}$ & $531 \mathrm{mg} \cdot \mathrm{dL}^{-1}$ & 2013 & [32] \\
\hline Dopamine & Metal electrode & OECT & $5 \mathrm{nM}$ & & 2011 & [47] \\
\hline $\begin{array}{l}\text { Glial fibrillary } \\
\text { acidic protein }\end{array}$ & GFAP antibodies & OTFT & $20 \mathrm{pM}$ & $20 \mathrm{nM}$ & 2014 & [46] \\
\hline BSA & Anti-BSA & OTFT & $1 \mu \mathrm{M}$ & $10 \mu \mathrm{M}$ & 2011 & [48] \\
\hline Anti-BSA & BSA & OTFT & $10 \mathrm{nM}$ & $2 \mu \mathrm{M}$ & 2011 & [49] \\
\hline $\mathrm{pH}$ & $\mathrm{n} / \mathrm{a}$ & Dual-gate OTFT & $\mathrm{pH} 2$ & $\mathrm{pH} 10$ & 2010 & [50] \\
\hline \multirow{5}{*}{ DNA } & Single-stranded DNA & OFET & $100 \mathrm{nM}$ & $50 \mu \mathrm{M}$ & 2010 & [39] \\
\hline & PNA & OTFT & $1 \mathrm{nM}$ & $100 \mathrm{nM}$ & 2010 & [40] \\
\hline & Single-stranded DNA & OECT & $10 \mathrm{pM}$ & $>1 \mu \mathrm{M}$ & 2011 & [43] \\
\hline & PNA & OTFT & $\sim 1 \mathrm{nM}$ & $\sim 100 \mathrm{nM}$ & 2012 & [42] \\
\hline & DNA & Water-gated OFET & $100 \mathrm{nM}$ & $\mathrm{n} / \mathrm{a}$ & 2012 & [41] \\
\hline
\end{tabular}

\section{Pressure Sensors}

There have been significant advances in recent years in the development of OTFTs and OTFT-based arrays designed for use in artificial intelligence applications, such as so-called "electronic skin" (e-skin) and "electronic nose" (e-nose). Someya and co-workers at the University of Tokyo were the first to publish reports outlining the development of what they dubbed "e-skin" [51-54]. The principles of e-skin are based on the detection of pressure and force either statically or dynamically. In these initial reports on e-skin, OTFTs, pressure-sensitive rubber and thermal sensors are combined to create fully flexible, pressure and temperature-sensitive artificial skin for use in the robotics industry. However, the pressure sensor arrays in the e-skin are not directly integrated with the transistors, but rather, are formed from a commercially available pressure-sensitive rubber containing carbon particles 
and a silicone rubber matrix, whilst the OTFTs act simply as signal transducers (see Figure 6). The electrical resistance between the top and bottom surfaces of the carbon-containing rubber material is a function of the mechanical deformation of the sheet and, thus, the pressure applied to it.

Similar devices utilizing pressure-sensitive rubber for pressure detection have also been based upon space-charge limited transistors (SCLT) with P3HT as the active layer [55]. An SCLT is a vertically configured transistor with a grid electrode inserted between the source electrode and the drain electrode to control the vertical current flow. As pressure is applied to the pressure-sensitive rubber, the resistance and, therefore, current in the source-drain circuit is systematically modulated, allowing the applied pressure to be monitored. Impressively, the response time of the sensor to the pressure is less than $22 \mathrm{~ms}$. A flexible pressure sensor has also been realized by using transparent plastic foil (Mylar), both as the substrate and gate dielectric [56,57]. Pressure was applied by the application of compressed air flow, and data analysis suggests that pressure-induced variations in $\mathrm{V}_{\mathrm{G}}$, threshold voltage and contact resistance are responsible for the current variations, but the mechanism of detection is not fully understood. Nonetheless, the changes in $I_{D}$ are reproducible. Moreover, the sensor responds very fast to a mechanical stimulus (tens to hundreds of milliseconds), but the time required to reach the steady state is much higher (tens to hundreds of seconds). A clever solution to pressure sensing has been offered by Kim et al. [58]. An OTFT pressure sensor based on soft-contact lamination was fabricated using an elastic polydimethylsiloxane (PDMS) mould with gold electrodes. The effective channel length of the laminated OTFT was controlled by external pressure on the structured PDMS mould; the observed changes in source-drain output currents, therefore, corresponded to these external loads without any change of the material properties. As a result of the elastic properties of the PDMS mould, the laminated device was returned to its former state after the external pressure was released. Based on this device property, reversible and time durable operations of the device were demonstrated. Using PDMS as the dielectric material and a designed microstructure array of pillars in the dielectric layer, Mannsfeld et al. demonstrated a highly sensitive, flexible bio-compatible pressure sensor for e-skin application [59]. Similarly, Kim, et al. used a nano-needle structured dielectric layer and showed a high sensitivity up to $1.76 \mathrm{kPa}^{-1}$, as determined by the normalized change of capacitance of the dielectric layer [60].

Figure 6. The structure of a pressure sensor (left) using a pressure-sensitive rubber as a transducer. Shown also is the thermal sensor (right) reported in the same publication.

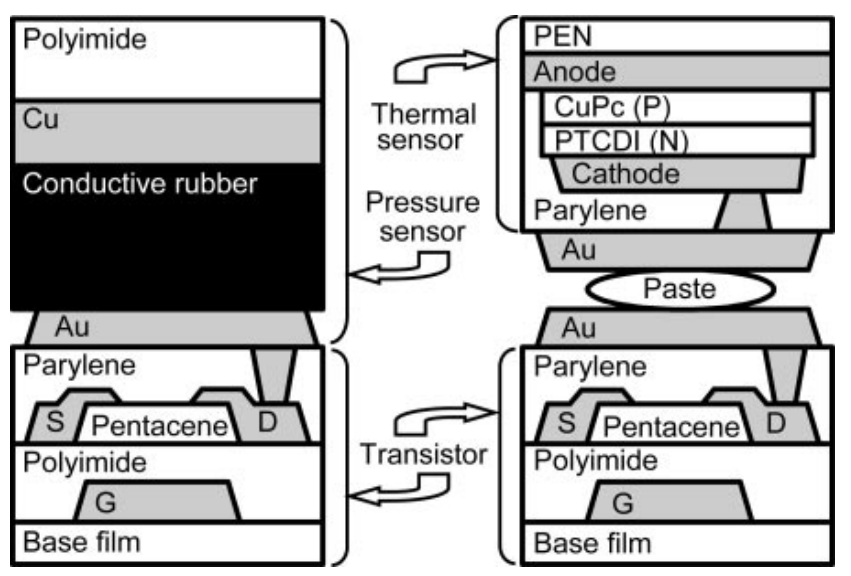

Copyright 2005 National Academy of Sciences, USA. Reproduced with permission from [52]. 
Furthermore, Darlinski et al. have shown that organic thin-film transistors are inherently sensitive to applied pressure [61]. The pressure dependence of pentacene transistors with a solution-processed polyvinylphenol gate dielectric on glass substrates was investigated by applying uniaxial mechanical pressure with a needle. The measurements showed a reversible current dependence of the transfer characteristics with $\mathrm{I}_{\mathrm{D}}$ reproducibly switching between two states. Experimental and simulation results suggested that turn-on voltage and interface resistance are being affected. However, the change takes of the order of seconds, hinting at charge trap states in the pentacene being responsible for the effect. This work demonstrated a much simpler way of making pressure sensors; however, the mechanism governing the sensitivity is yet to be understood. Cosseddu, Milita and Bonfiglio also showed that pentacene is a better electromechanical material than P3HT for the fabrication of low-cost pressure sensors, due to the low crystallinity of the P3HT thin film, making it less sensitive to any deformation [62].

More recently, Schwartz and co-workers reported using a micro-structured PDMS dielectric: the pressure-sensitive OTFT achieved a maximum sensitivity of $8.4 \mathrm{kPa}^{-1}$ (in terms of a normalized change in $\mathrm{I}_{\mathrm{D}}$ ). Furthermore, a fast response time of less than $10 \mathrm{~ms}$, high stability (more than 15,000 cycles) and a power consumption of less than $1 \mathrm{~mW}$ were achieved. [63]. Lai and co-workers reported the use of a PDMS capacitive sensor and a floating gate, showing that it is also feasible to fabricate a pressure sensor for artificial skin [64]. This type of device works at $-2 \mathrm{~V}$ for both $\mathrm{V}_{\mathrm{D}}$ and $\mathrm{V}_{\mathrm{G}}$, making it easily operable from batteries.

Organic transistor-based pressure sensors have shown much promise for e-skin applications, and the mechanisms used are varied. Table 2 summarizes the organic transistor-based pressure sensors presented here, their device structure, sensitivity and the operation mechanism that results in the sensing effects. Few of the discussed papers mention the details about the exact device pressure sensitivity and the response time. There is little known about what the critical criteria are that make effective artificial skin in terms of the sensitivity and response time. In addition, it is still questionable whether large area pressure sensing is achievable under the reported device architectures for e-skin applications. For an OTFT-based pressure sensor, whether it is necessary to demand device operation at low voltages for health, safety and power consumption concerns is dependent on the application.

Table 2. A summary of the pressure-sensing devices discussed in this review.

\begin{tabular}{cccccc}
\hline Device Materials/Structure & Sensitivity & Response Time & $\begin{array}{c}\text { Current Modulation } \\
\text { Mechanism }\end{array}$ & Year & Ref. \\
\hline $\begin{array}{c}\text { Polyimide/pentacene/ } \\
\text { conductive rubber network }\end{array}$ & $30 \mathrm{kPa}^{-1}$ & $\mathrm{n} / \mathrm{a}$ & $\begin{array}{c}\text { Pressure- and } \\
\text { thermal-sensitive } \\
\text { materials }\end{array}$ & 2004 & {$[51]$} \\
\hline $\begin{array}{c}\text { Graphite containing } \\
\text { rubber/pentacene }\end{array}$ & $30 \mathrm{kPa}^{-1}$ & $\begin{array}{c}\text { Hundreds of } \\
\text { milliseconds }\end{array}$ & $\begin{array}{c}\text { Change in } \\
\text { transconductance }\end{array}$ & 2005 & {$[52]$} \\
\hline $\begin{array}{c}\text { Single-walled carbon nanotubes } \\
\text { as a conducting dopant in a } \\
\text { rubber, FET matrix }\end{array}$ & $\mathrm{n} / \mathrm{a}$ & $\mathrm{n} / \mathrm{a}$ & $\begin{array}{c}\text { Pressure-sensitive } \\
\text { rubber conductor }\end{array}$ & 2010 & {$[53]$} \\
\hline $\begin{array}{c}\text { Ionic liquid/conductive } \\
\text { rubber/sensor array }\end{array}$ & $30 \mathrm{kPa}^{-1}$ & $\mathrm{n} / \mathrm{a}$ & $\begin{array}{c}\text { Tension-dependent } \\
\text { conductive rubber }\end{array}$ & 2010 & {$[54]$} \\
\hline
\end{tabular}


Table 2. Cont.

\begin{tabular}{|c|c|c|c|c|c|}
\hline Device Materials/Structure & Sensitivity & Response Time & $\begin{array}{c}\text { Current Modulation } \\
\text { Mechanism }\end{array}$ & Year & Ref. \\
\hline Pressure-sensitive rubber & $\mathrm{n} / \mathrm{a}$ & $22 \mathrm{~ms}$ & $\begin{array}{c}\text { Space charge limited, } \\
\text { low voltage operation } \\
\text { at } \sim 3 \mathrm{~V} \\
\end{array}$ & 2009 & [55] \\
\hline $\begin{array}{l}\text { Plastic foil as dielectric layer } \\
\text { (Mylar) }\end{array}$ & $\mathrm{n} / \mathrm{a}$ & $\begin{array}{c}\text { Tens to hundreds } \\
\text { of seconds } \\
\end{array}$ & $\begin{array}{c}\text { Mobility or interface } \\
\text { effects }\end{array}$ & 2007 & [56] \\
\hline $\begin{array}{l}\text { Plastic foil as dielectric layer } \\
\text { (Mylar) }\end{array}$ & $\mathrm{n} / \mathrm{a}$ & $\begin{array}{c}\text { Tens to hundreds } \\
\text { of seconds }\end{array}$ & Interface effects & 2006 & {$[57]$} \\
\hline PDMS mould on gold & $\begin{array}{c}0.14 \sim 0.3\left(\mathrm{~N} / \mathrm{mm}^{2}\right)^{-1} \\
\text { or } 140 \sim 300 \mathrm{kPa}^{-1}\end{array}$ & $\mathrm{n} / \mathrm{a}$ & $\begin{array}{l}\text { Pressure dependent } \\
\text { channel length }\end{array}$ & 2010 & [58] \\
\hline $\begin{array}{c}\text { Microstructured PDMS } \\
\text { dielectric layer, rubrene } \\
\text { semiconducting layer } \\
\end{array}$ & $\mathrm{n} / \mathrm{a}$ & Millisecond range & Capacitive effect & 2010 & [59] \\
\hline Nano-needle dielectric layer & $1.76 \mathrm{kPa}^{-1}$ & $\mathrm{n} / \mathrm{a}$ & $\begin{array}{c}\text { The sharpness of the } \\
\text { nano-needles }\end{array}$ & 2012 & {$[60]$} \\
\hline PVP/Pentacene & $\mathrm{n} / \mathrm{a}$ & $20 \mathrm{~s}$ & Trapped charges & 2005 & [61] \\
\hline $\begin{array}{c}\text { Devices with P3HT and } \\
\text { pentacene semiconducting } \\
\text { layers }\end{array}$ & $\mathrm{n} / \mathrm{a}$ & $100 \mathrm{~ms}$ & $\begin{array}{l}\text { P3HT layer is less } \\
\text { crystalline than } \\
\text { pentacene }\end{array}$ & 2012 & [62] \\
\hline $\begin{array}{l}\text { Microstructured PDMS dielectric } \\
\text { and polyisoindigobithiophene- } \\
\text { siloxane semiconductor }\end{array}$ & $8.4 \mathrm{kPa}^{-1}$ & Less than $10 \mathrm{~ms}$ & $\begin{array}{c}\text { Operating device in } \\
\text { the sub-threshold } \\
\text { regime }\end{array}$ & 2013 & [63] \\
\hline $\begin{array}{l}\text { PDMS dielectric layer with a } \\
\text { floating gate }\end{array}$ & $\mathrm{n} / \mathrm{a}$ & $\mathrm{n} / \mathrm{a}$ & $\begin{array}{l}\text { Ultra-low voltage } \\
\text { operation, variation in } \\
\text { the PDMS capacitance }\end{array}$ & 2013 & [64] \\
\hline
\end{tabular}

\section{Vapour Sensing}

In 1982, Persaud and Dodd first proposed the concept of an artificial nose, which operates as a gas sensor for the recognition of odours [65]. Later, the term "e-nose" was used to describe a sensing device resembling a mammalian nose to detect various gases. There is only a very limited amount of work published so far on OTFT-based systems suitable for e-nose applications. Ideally, an e-nose sensor should satisfy the following criteria: high sensitivity to chemical compounds, low sensitivity to humidity and temperature, high stability, high reproducibility, fast response time, robust, easy calibration and small physical dimensions [66]. Most work published on OTFT-based gas sensors have shown that they satisfy one or two aspects of the above criteria, thus making them potential candidates for use in an e-nose.

In 2005, Liao et al. reported on a back-gated OTFT in which the sensor material is also the active layer for the transistor itself. Toluene and propanol have been tested, and the OTFT devices are sensitive towards exposure to the gas pressure. The authors also showed the OTFT potentially are able to discriminate between water and milk [67]. Li and Lambeth showed that using a nanostructured rr-P3HT as the active layer, OTFTs show sensitivity to 10 analytes, although the device responses are 
different for polar and nonpolar gases. The authors attributed the sensing behaviour to the grain boundary effect, which affects OTFT charge transport [68]. Wedge and co-workers using a four-OTFT array structure and an amorphous semiconductor, polytriarylamines (PTAAs), as the active layer and sensing material, combined with a genetic programming pattern recognition, successfully produced a vapour sensor with high sensitivity and specificity [69]. Liao and co-workers tested the effects of the side chain length of polythiophene and the film thickness in the active layer, together with the size of analytes on the sensing responses. They found that the OTFT based sensors can map out different amine gas mixtures [70]. Wang and Swensen proposed a dual-mode sensing approach by utilizing a set of different and independent transduction signals for vapour detection. They employed luminescent organic semiconductors as the active layer materials, which produce both electrical and optical signals under gate modulation. They demonstrated that these OTFT-based sensors can be used to detect the explosive vapour. However, the operation voltage is quite high (more than $50 \mathrm{~V}$ ) [71].

Explosive detection has also been explored with encouraging results, firstly by Huang et al. in 2010 [72] and also by Kong et al. in 2012 [73]. More recently, Kybert et al. reported that by using functionalized carbon nanotubes as the active layer and incorporating single-stranded DNA as the sensing agent, so-called "DNA-NT OTFT" gas sensors can be fabricated. The device responds to both the DNA sequence and the analytes, showing a positive response to D-limonene and a negative response to L-limonene, as well as being able to distinguish the isomers of pinene [74].

We propose that one of the reasons for the relatively small number of publications on OTFT-based sensors for "e-nose" applications is due to there being limited options for materials suitable for the semiconducting layer in an OTFT that are also effective for selective gas sensing. Only the bottom gate architecture is feasible if the active layer materials must play these dual roles in the sensors. The sensing signal is triggered by the electrical change in the channel and magnified by the $\mathrm{V}_{\mathrm{G}}$ modulation. More exploration on the incorporation of chemically-sensitive elements into the OTFT channel appears to be a desirable line of investigation in the coming years.

\section{Conclusions}

In conclusion, the three types of OTFT-based sensors covered in this review show much promise for their eventual integration into applications outside the laboratory. Two distinct strategies have been used in the development of devices for OTFT-based sensing applications. Firstly, for a multiple-layer, structured OTFT, the organic materials used in the construction of the OTFTs themselves can also probe the analytes and induce changes in the conductivity of the source-drain channel. By measuring the change in the electrical signal in the channel, sensing responses can be quantified in a straightforward manner. The other method requires embedding an extra material, that is a sensitive and selective recognition element, into the device. The former is stricter on the material suitability, and in the latter, material compatibility is more critical. It is also desirable to have the operation voltages below $5 \mathrm{~V}$ for a portable, battery-powered device, which is possible for most OTFT-based sensors reported in this review. Progress in recent years has shown both increases in the sensitivity and selectivity of OTFT-based sensors, as well as the range of analytes targeted by such devices. Recent advances, along with the potential for economies of scale in the large-scale fabrication of organic electronic devices in 
general, gives optimism that reliable, low-cost OTFT-based sensors will be produced in the not-too-distant future.

\section{Conflicts of Interest}

The authors declare no conflict of interest.

\section{References}

1. Dimitrakopoulos, C.D.; Mascaro, D.J. Organic thin-film transistors: A review of recent advances. IBM J. Res. Dev. 2001, 45, 11-27.

2. Katz, H.E. Recent advances in semiconductor performance and printing processes for organic transistor-based electronics. Chem. Mater. 2004, 16, 4748-4756.

3. Lin, P.; Yan, F. Organic thin-film transistors for chemical and biological sensing. Adv. Mater. 2012, 24, 34-51.

4. Liao, C.; Yan, F. Organic semiconductors in organic thin-film transistor-based chemical and biological sensors. Polym. Rev. 2013, 53, 352-406.

5. Vieira, N.C.S.; Fernandes, E.G.R.; de Queiroz, A.A.A.; Guimarães, F.E.G.; Zucolotto, V. Indium tin oxide synthesized by a low cost route as segfet ph sensor. Mater. Res. 2013, 16, 1156-1160.

6. Kergoat, L.; Piro, B.; Berggren, M.; Horowitz, G.; Pham, M.-C. Advances in organic transistor-based biosensors: From organic electrochemical transistors to electrolyte-gated organic field-effect transistors. Anal. Bioanal. Chem. 2012, 402, 1813-1826.

7. Schmoltner, K.; Kofler, J.; Klug, A.; List-Kratochvil, E.J.W. Electrolyte-gated organic field-effect transistor for selective reversible ion detection. Adv. Mater. 2013, 25, 6895-6899.

8. Loi, A.; Manunza, I.; Bonfiglio, A. Flexible, organic, ion-sensitive field-effect transistor. Appl. Phys. Lett. 2005, 86, 103512, doi:10.1063/1.1873051.

9. Sandberg, H.G.O.; Bäcklund, T.G.; Österbacka, R.; Stubb, H. High-performance all-polymer transistor utilizing a hygroscopic insulator. Adv. Mater. 2004, 16, 1112-1115.

10. Deng, J.; Patil, N.; Ryu, K.; Badmaev, A.; Zhou, C.; Mitra, S.; Wong, H.-S. Carbon nanotube Transistor Circuits: Circuit-Level Performance Benchmarking and Design Options for Living with Imperfections. In Proceedings of the IEEE International Solid-State Circuits Conference, 2007, ISSCC 2007, Digest of Technical Papers, San Francisco, CA, USA, 11-15 Febuary 2007; pp. 70-588.

11. Justino, C.I.; Freitas, A.C.; Amaral, J.P.; Rocha-Santos, T.A.; Cardoso, S.; Duarte, A.C. Disposable immunosensors for c-reactive protein based on carbon nanotubes field effect transistors. Talanta 2013, 108, 165-170.

12. Lai, S.; Demelas, M.; Casula, G.; Cosseddu, P.; Barbaro, M.; Bonfiglio, A. Ultralow voltage, otft-based sensor for label-free DNA detection. Adv. Mater. 2013, 25, 103-107.

13. Demelas, M.; Lai, S.; Spanu, A.; Martinoia, S.; Cosseddu, P.; Barbaro, M.; Bonfiglio, A. Charge sensing by organic charge-modulated field effect transistors: Application to the detection of bio-related effects. J. Mater. Chem. B 2013, 1, 3811-3819.

14. Bartic, C.; Campitelli, A.; Borghs, S. Field-effect detection of chemical species with hybrid organic/inorganic transistors. Appl. Phys. Lett. 2003, 82, 475-477. 
15. Magliulo, M.; Pistillo, B.R.; Mulla, M.Y.; Cotrone, S.; Ditaranto, N.; Cioffi, N.; Favia, P.; Torsi, L. PE-CVD of hydrophilic-COOH functionalized coatings on electrolyte gated field-effect transistor electronic layers. Plasma Process. Polym. 2013, 10, 102-109.

16. IUPAC. Compendium of Chemical Terminology, 2nd ed.; Blackwell Scientific Publications: Oxford, UK, 1997.

17. Clark, L.C.; Lyons, C. Electrode systems for continuous monitoring in cardiovascular surgery. Ann. N. Y. Acad. Sci. 1962, 102, 29-45.

18. Heller, A. Implanted electrochemical glucose sensors for the management of diabetes. Annu. Rev. Biomed. Eng. 1999, 1, 153-175.

19. Wilson, R.; Turner, A.P.F. Glucose oxidase: An ideal enzyme. Biosens. Bioelectron. 1992, 7 , 165-185.

20. Macaya, D.J.; Nikolou, M.; Takamatsu, S.; Mabeck, J.T.; Owens, R.M.; Malliaras, G.G. Simple glucose sensors with micromolar sensitivity based on organic electrochemical transistors. Sens. Actuators B 2007, 123, 374-378.

21. Umana, M.; Waller, J. Protein-modified electrodes. The glucose oxidase/polypyrrole system. Anal. Chem. 1986, 58, 2979-2983.

22. Bartlett, P.N.; Whitaker, R.G. Electrochemical immobilisation of enzymes: Part II. Glucose oxidase immobilised in poly-n-methylpyrrole. J. Electroanal. Chem. 1987, 224, 37-48.

23. Zhu, Z.-T.; Mabeck, J.T.; Zhu, C.; Cady, N.C.; Batt, C.A.; Malliaras, G.G. A simple poly(3,4-ethylene dioxythiophene)/poly(styrene sulfonic acid) transistor for glucose sensing at neutral $\mathrm{pH}$. Chem. Commun. 2004, 1556-1557.

24. Bernards, D.A.; Macaya, D.J.; Nikolou, M.; DeFranco, J.A.; Takamatsu, S.; Malliaras, G.G. Enzymatic sensing with organic electrochemical transistors. J. Mater. Chem. 2007, 18, 116-120.

25. Liu, J.; Agarwal, M.; Varahramyan, K. Glucose sensor based on organic thin film transistor using glucose oxidase and conducting polymer. Sens. Actuators B: Chem. 2008, 135, 195-199.

26. Liao, C.; Zhang, M.; Niu, L.; Zheng, Z.; Yan, F. Highly selective and sensitive glucose sensors based on organic electrochemical transistors with graphene-modified gate electrodes. J. Mater. Chem. B 2013, 1, 3820-3829.

27. Liao, C.; Zhang, M.; Niu, L.; Zheng, Z.; Yan, F. Organic electrochemical transistors with graphene-modified gate electrodes for highly sensitive and selective dopamine sensors. J. Mater. Chem. B 2014, 2, 191-200.

28. Tang, H.; Yan, F.; Lin, P.; Xu, J.; Chan, H.L. Highly sensitive glucose biosensors based on organic electrochemical transistors using platinum gate electrodes modified with enzyme and nanomaterials. Adv. Funct. Mater. 2011, 21, 2264-2272.

29. Wang, Z.; Gao, J. Research on the urease biosensor with ppy material as carrier and sensitive membrane. In Proceedings of the 2010 3rd International Conference on Biomedical Engineering and Informatics (BMEI), Yantai, China, 16-18 October 2010; pp. 1574-1576.

30. Buth, F.; Donner, A.; Sachsenhauser, M.; Stutzmann, M.; Garrido, J.A. Biofunctional electrolyte-gated organic field-effect transistors. Adv. Mater. 2012, 24, 4511-4517.

31. Khodagholy, D.; Curto, V.F.; Fraser, K.J.; Gurfinkel, M.; Byrne, R.; Diamond, D.; Malliaras, G.G.; Benito-Lopez, F.; Owens, R.M. Organic electrochemical transistor incorporating an ionogel as a solid state electrolyte for lactate sensing. J. Mater. Chem. 2012, 22, 4440-4443. 
32. Phongphut, A.; Sriprachuabwong, C.; Wisitsoraat, A.; Tuantranont, A.; Prichanont, S.; Sritongkham, P. A disposable amperometric biosensor based on inkjet-printed au/pedot-pss nanocomposite for triglyceride determination. Sens. Actuators B 2013, 178, 501-507.

33. Jia, W.; Bandodkar, A.J.; Valdes-Ramirez, G.; Windmiller, J.R.; Yang, Z.; Ramirez, J.; Chan, G.; Wang, J. Electrochemical tattoo biosensors for real-time noninvasive lactate monitoring in human perspiration. Anal. Chem. 2013, 85, 6553-6560.

34. Vieira, N.C.S.; Figueiredo, A.; Fernandes, E.G.R.; Guimarães, F.E.G.; Zucolotto, V. Nanostructured polyaniline thin films as urea-sensing membranes in field-effect devices. Synth. Met. 2013, 175, 108-111.

35. Someya, T.; Dodabalapur, A.; Gelperin, A.; Katz, H.E.; Bao, Z. Integration and response of organic electronics with aqueous microfluidics. Langmuir 2002, 18, 5299-5302.

36. Magliulo, M.; Mallardi, A.; Gristina, R.; Ridi, F.; Sabbatini, L.; Cioffi, N.; Palazzo, G.; Torsi, L. Part per trillion label-free electronic bioanalytical detection. Anal. Chem. 2013, 85, 3849-3857.

37. Magliulo, M.; Mallardi, A.; Mulla, M.Y.; Cotrone, S.; Pistillo, B.R.; Favia, P.; Vikholm-Lundin, I.; Palazzo, G.; Torsi, L. Electrolyte-gated organic field-effect transistor sensors based on supported biotinylated phospholipid bilayer. Adv. Mater. 2013, 25, 2090-2094.

38. Chartuprayoon, N.; Rheem, Y.; Ng, J.C.; Nam, J.; Chen, W.; Myung, N.V. Polypyrrole nanoribbon based chemiresistive immunosensor for viral plant pathogen detection. Anal. Methods 2013, 5, 3497-3502.

39. Lin, T.-W.; Kekuda, D.; Chu, C.-W. Label-free detection of DNA using novel organic-based electrolyte-insulator-semiconductor. Biosens. Bioelectron. 2010, 25, 2706-2710.

40. Khan, H.U.; Roberts, M.E.; Johnson, O.; Förch, R.; Knoll, W.; Bao, Z. In situ, label-free DNA detection using organic transistor sensors. Adv. Mater. 2010, 22, 4452-4456.

41. Kergoat, L.; Piro, B.; Berggren, M.; Pham, M.-C.; Yassar, A.; Horowitz, G. DNA detection with a water-gated organic field-effect transistor. Org. Electron. 2012, 13, 1-6.

42. Khan, H.U.; Roberts, M.E.; Johnson, O.; Knoll, W.; Bao, Z. The effect of ph and DNA concentration on organic thin-film transistor biosensors. Org. Electron. 2012, 13, 519-524.

43. Lin, P.; Luo, X.; Hsing, I.; Yan, F. Organic electrochemical transistors integrated in flexible microfluidic systems and used for label-free DNA sensing. Adv. Mater. 2011, 23, 4035-4040.

44. Hammock, M.L.; Knopfmacher, O.; Naab, B.D.; Tok, J.B.-H.; Bao, Z. Investigation of protein detection parameters using nano-functionalized organic field-effect transistors. ACS Nano 2013, 7, 3970-3980.

45. Tarabella, G.; Balducci, A.G.; Coppedè, N.; Marasso, S.; D’Angelo, P.; Barbieri, S.; Cocuzza, M.; Colombo, P.; Sonvico, F.; Mosca, R. Liposome sensing and monitoring by organic electrochemical transistors integrated in microfluidics. Biochim. Biophys. Acta 2013, 1830, 4374-4380.

46. Huang, W.; Besar, K.; LeCover, R.; Dulloor, P.; Sinha, J.; Hardigree, J.F.M.; Pick, C.; Swavola, J.; Everett, A.D.; Frechette, J. Label-free brain injury biomarker detection based on highly sensitive large area organic thin film transistor with hybrid coupling layer. Chem. Sci. 2014, 5, 416-426.

47. Tang, H.; Lin, P.; Chan, H.L.; Yan, F. Highly sensitive dopamine biosensors based on organic electrochemical transistors. Biosens. Bioelectron. 2011, 26, 4559-4563.

48. Khan, H.U.; Jang, J.; Kim, J.-J.; Knoll, W. Effect of passivation on the sensitivity and stability of pentacene transistor sensors in aqueous media. Biosens. Bioelectron. 2011, 26, 4217-4221. 
49. Khan, H.U.; Jang, J.; Kim, J.-J.; Knoll, W. In situ antibody detection and charge discrimination using aqueous stable pentacene transistor biosensors. J. Am. Chem. Soc. 2011, 133, 2170-2176.

50. Spijkman, M.J.; Brondijk, J.J.; Geuns, T.C.; Smits, E.C.; Cramer, T.; Zerbetto, F.; Stoliar, P.; Biscarini, F.; Blom, P.W.; de Leeuw, D.M. Dual-gate organic field-effect transistors as potentiometric sensors in aqueous solution. Adv. Funct. Mater. 2010, 20, 898-905.

51. Someya, T.; Sekitani, T.; Iba, S.; Kato, Y.; Kawaguchi, H.; Sakurai, T. A large-area, flexible pressure sensor matrix with organic field-effect transistors for artificial skin applications. Proc. Natl. Acad. Sci. USA 2004, 101, 9966-9970.

52. Someya, T.; Kato, Y.; Sekitani, T.; Iba, S.; Noguchi, Y.; Murase, Y.; Kawaguchi, H.; Sakurai, T. Conformable, flexible, large-area networks of pressure and thermal sensors with organic transistor active matrixes. Proc. Natl. Acad. Sci. USA 2005, 102, 12321-12325.

53. Sekitani, T.; Someya, T. Stretchable, large-area organic electronics. Adv. Mater. 2010, 22, 2228-2246.

54. Someya, T.; Dodabalapur, A.; Huang, J.; See, K.C.; Katz, H.E. Chemical and physical sensing by organic field-effect transistors and related devices. Adv. Mater. 2010, 22, 3799-3811.

55. Chao, Y.-C.; Lai, W.-J.; Chen, C.-Y.; Meng, H.-F.; Zan, H.-W.; Horng, S.-F. Low voltage active pressure sensor based on polymer space-charge-limited transistor. Appl. Phys. Lett. 2009, 95, 253306, doi:10.1063/1.3266847.

56. Manunza, I.; Bonfiglio, A. Pressure sensing using a completely flexible organic transistor. Biosens. Bioelectron. 2007, 22, 2775-2779.

57. Manunza, I.; Sulis, A.; Bonfiglio, A. Pressure sensing by flexible, organic, field effect transistors. Appl. Phys. Lett. 2006, 89, 143502, doi:10.1063/1.2357924.

58. Kim, J.-H.; Sun, Q.; Seo, S. Pressure dependent current-controllable devices based on organic thin film transistors by soft-contact lamination. Org. Electron. 2010, 11, 964-968.

59. Mannsfeld, S.C.; Tee, B.C.; Stoltenberg, R.M.; Chen, C.V.H.; Barman, S.; Muir, B.V.; Sokolov, A.N.; Reese, C.; Bao, Z. Highly sensitive flexible pressure sensors with microstructured rubber dielectric layers. Nat. Mater. 2010, 9, 859-864.

60. Kim, J.; Nga Ng, T.; Soo Kim, W. Highly sensitive tactile sensors integrated with organic transistors. Appl. Phys. Lett. 2012, 101, 103308, doi:10.1063/1.4751354.

61. Darlinski, G.; Bottger, U.; Waser, R.; Klauk, H.; Halik, M.; Zschieschang, U.; Schmid, G.; Dehm, C. Mechanical force sensors using organic thin-film transistors. J. App. Phys. 2005, 97, 093708, doi:10.1063/1.1888046

62. Cosseddu, P.; Milita, S.; Bonfiglio, A. Strain sensitivity and transport properties in organic field-effect transistors. IEEE Electron Device Lett. 2012, 33, 113-115.

63. Schwartz, G.; Tee, B.C.-K.; Mei, J.; Appleton, A.L.; Wang, H.; Bao, Z. Flexible polymer transistors with high pressure sensitivity for application in electronic skin and health monitoring. Nat. Commun. 2013, 4, 1859, doi:10.1038/ncomms2832.

64. Lai, S.; Cosseddu, P.; Bonfiglio, A.; Barbaro, M. Ultralow voltage pressure sensors based on organic fets and compressible capacitors. IEEE Electron Device Lett. 2013, 34, 801-803.

65. Persaud, K.; Dodd, G. Analysis of discrimination mechanisms in the mammalian olfactory system using a model nose. Nature 1982, 299, 352-355.

66. Schaller, E.; Bosset, J.O.; Escher, F. 'Electronic noses' and their application to food. LWT_Food Sci. Technol. 1998, 31, 305-316. 
67. Liao, F.; Chen, C.; Subramanian, V. Organic tfts as gas sensors for electronic nose applications. Sens. Actuators B 2005, 107, 849-855.

68. Li, B.; Lambeth, D.N. Chemical sensing using nanostructured polythiophene transistors. Nano Lett. 2008, 8, 3563-3567.

69. Wedge, D.C.; Das, A.; Dost, R.; Kettle, J.; Madec, M.-B.; Morrison, J.J.; Grell, M.; Kell, D.B.; Richardson, T.H.; Yeates, S. Real-time vapour sensing using an OFET-based electronic nose and genetic programming. Sens. Actuators B 2009, 143, 365-372.

70. Liao, F.; Yin, S.; Toney, M.; Subramanian, V. Physical discrimination of amine vapor mixtures using polythiophene gas sensor arrays. Sens. Actuators B 2010, 150, 254-263.

71. Wang, L.; Swensen, J.S. Dual-transduction-mode sensing approach for chemical detection. Sens. Actuators B 2012, 174, 366-372.

72. Huang, J.; Dawidczyk, T.; Jung, B.; Sun, J.; Mason, A.; Katz, H. Response diversity and dual response mechanism of organic field-effect transistors with dinitrotoluene vapor. J. Mater. Chem. 2010, 20, 2644-2650.

73. Kong, H.; Jung, B.J.; Sinha, J.; Katz, H.E. Electrical "turn-on" response of poly (3,3"'-didodecylquaterthiophene) and electron donor blend transistors to 2,4,6-trinitrotoluene. Chem. Mater. 2012, 24, 2621-2623.

74. Kybert, N.J.; Lerner, M.B.; Yodh, J.S.; Preti, G.; Johnson, A.C. Differentiation of complex vapor mixtures using versatile DNA-carbon nanotube chemical sensor arrays. ACS Nano 2013, 7 , 2800-2807.

(C) 2014 by the authors; licensee MDPI, Basel, Switzerland. This article is an open access article distributed under the terms and conditions of the Creative Commons Attribution license (http://creativecommons.org/licenses/by/3.0/). 